\title{
Venous Thromboembolism Prophylaxis on General Internal Medicine Units: Are Patients Well Served by Current Practice?
}

\author{
Allison Mejilla, Micheal Guirguis, Sheri Koshman, and Tammy J Bungard
}

\begin{abstract}
Background: Venous thromboembolism (VTE) is the most preventable hospital-associated complication, and implementation of appropriate VTE prophylaxis is a requirement for institutional accreditation. However, ambiguity and controversy exist within current recommendations, and greater clarity about and understanding of current utilization of VTE prophylaxis may be needed.

Objectives: The primary objective was to assess the proportion of patients receiving appropriate VTE prophylaxis (right drug, dose, frequency, and duration) within $24 \mathrm{~h}$ after admission to general internal medicine units. The secondary objectives were to determine the proportion of at-risk patients who experienced adverse events (major bleeding or thrombotic events) in relation to appropriateness of prophylaxis, to describe reasons why VTE prophylaxis was inappropriate, and to compare these findings with local audit data.
\end{abstract}

Methods: This cross-sectional study involved adult patients at moderate to very high risk of VTE who were discharged from general internal medicine units between January 1 and September 30, 2015, at the University of Alberta Hospital in Edmonton, Alberta. Patients with length of stay less than $72 \mathrm{~h}$, those already receiving therapeutic anticoagulation, and those lacking documentation of renal function or weight were excluded. A paired $t$ test was used to compare the study data with audit results.

Results: Of 225 patients identified as being at risk of VTE, 179 (79.6\%) received appropriate prophylaxis. The most common reasons why VTE prophylaxis was deemed inappropriate were not providing a mechanical method of prophylaxis for patients with bleeding contraindications (18/46 [39.1\%]) and incorrect dose of pharmacologic prophylaxis (15/46 [32.6\%]). The rate of appropriate VTE prophylaxis was lower than that reported in local audits $(79.6 \%$ versus $97.6 \% ; p=0.002)$. Adverse events were less frequent among those receiving appropriate VTE prophylaxis than among those receiving inappropriate prophylaxis: $1.7 \%(3 / 179)$ versus $6.5 \%$ (3/46) for thrombotic events and $4.5 \%$ (8/179) versus $19.6 \%$ (9/46) for major bleeding.

Conclusions: These results provide insight into current prescribing patterns for VTE prophylaxis and highlight the need for continued engagement of the health care team in the provision of appropriate VTE prophylaxis.

\section{RÉSUMÉ}

Contexte : La thromboembolie veineuse (TEV) est la complication iatrogénique la plus facilement évitable chez les patients hospitalisés. D'ailleurs, la mise en place d'une prophylaxie adéquate de la TEV est exigée pour obtenir l'agrément institutionnel. Cependant, l'ambiguïté qui plane sur les recommandations actuelles crée une certaine controverse. Il pourrait donc être nécessaire de clarifier l'utilisation de la prophylaxie de la TEV et de chercher à mieux la comprendre.

Objectifs : L'objectif principal était d'évaluer la proportion de patients recevant la prophylaxie adéquate de la TEV (le bon médicament ainsi que la durée, la dose et la fréquence exactes) dans les 24 heures suivant l'admission aux services de médecine interne générale. Les objectifs secondaires étaient d'abord de déterminer la proportion de patients à risque ayant subi des événements indésirables (saignement important ou événement thrombotique) par rapport à la pertinence de la prophylaxie; ensuite, de décrire les raisons expliquant pourquoi la prophylaxie de la TEV était jugée inadéquate; et, enfin, de comparer ces résultats aux données de vérifications locales.

Méthodes : La présente étude descriptive et transversale a été menée auprès de patients adultes qui présentaient un risque allant de modéré à très élevé de TEV et qui avaient reçu leur congé des services de médecine interne générale de l'Hôpital de l'Université de l'Alberta à Edmonton, en Alberta, entre le $1^{\text {er }}$ janvier et le 30 septembre 2015. Les patients hospitalisés pendant moins de 72 heures, ceux qui recevaient déjà une anticoagulothérapie et ceux pour qui l'on ne disposait pas des renseignements sur le poids ou la fonction rénale ont été exclus. Un test $t$ pour échantillons appariés a été utilisé pour effectuer la comparaison entre les données de l'étude et celles de la vérification.

Résultats : Parmi les 225 patients identifiés comme étant à risque de TEV, $179(79,6 \%)$ ont reçu la prophylaxie adéquate. Les raisons les plus souvent évoquées pour juger inadéquate la prophylaxie de la TEV étaient l'absence du recours à une méthode mécanique pour les patients présentant des contre-indications liées au saignement (18/46 [39,1\%]) et la prescription de doses erronées (15/46 [32,6\%]). Le taux de prophylaxie adéquate de la TEV était plus faible que les valeurs observées dans les vérifications locales $(79,6 \%$ contre $97,6 \% ; p=0.002)$. Les événements indésirables étaient moins fréquents chez les patients ayant reçu une prophylaxie adéquate de la TEV que chez ceux ayant reçu une 
This single copy is for your personal, non-commercial use only.

For permission to reprint multiple copies or to order presentation-ready copies for distribution, contact CJHP at cjhpedit@cshp.ca

Keywords: venous thromboembolism prophylaxis, health care quality

Can J Hosp Pharm. 2017;70(3):200-6 prophylaxie inadéquate : 2,7 \% (5/179) contre 6,5\% (3/46) pour les événements thrombotiques et 4,5\% (8/179) contre 19,6\% (9/46) pour les hémorragies importantes.

Conclusions : Ces résultats offrent une meilleure compréhension des habitudes de prescription actuelle concernant la prophylaxie de la TEV. Ils soulignent aussi la nécessité d'une participation constante de l'équipe de soins de santé à la fourniture d'une prophylaxie adéquate de la TEV.

Mots clés : prophylaxie de la thromboembolie veineuse, qualité des soins de santé

\section{INTRODUCTION}

$\mathrm{V}$ enous thromboembolism (VTE), comprising deep vein thrombosis and pulmonary embolism, is the third most common cardiovascular disease after myocardial infarction and stroke. ${ }^{1}$ Admission to hospital increases an individual's risk for VTE 8-fold, and VTE is the most common preventable cause of death in hospitals ${ }^{2-5}$; as such, VTE prophylaxis is ranked the number 1 patient safety intervention by the US Agency for Healthcare Research and Quality. ${ }^{3,6}$ Accordingly, implementation of VTE prophylaxis is necessary for institutional accreditation through Accreditation Canada. ${ }^{2,3,5,7}$ Accreditation Canada allows institutions to set their own VTE prophylaxis targets, with no minimum target. Alberta Health Services (AHS) has established a target of providing appropriate VTE prophylaxis to $85 \%$ of eligible patients, to be achieved by each institution within the province.

Safer Healthcare Now, a program of the Canadian Patient Safety Institute, continually monitors Canadian rates of appropriate VTE prophylaxis and barriers to VTE prophylactic prescribing by collecting and analyzing data from local audits, such as those performed by AHS. ${ }^{8}$ These local "spot" audits, which demonstrate site commitment to appropriate VTE prophylaxis, have small patient samples (typically 10-20 patients), use liberal definitions of appropriate VTE prophylaxis (e.g., including graduated compression stockings), and have consistently shown high rates of appropriate VTE prophylaxis. The aggregated VTE prophylaxis rates from local audits are then reported as measures of appropriateness nationally and provincially. ${ }^{8}$

Complicating the determination of appropriateness of VTE prophylaxis is the fact that current evidence-based guidelines vary according to risk of thrombosis, risk of bleeding, weight, renal function, and current health status. ${ }^{3,4}$ In spite of several evidencebased guidelines and the multitude of studies stating that VTE prophylaxis is safe, effective, and cost-effective in moderate-risk patients, ${ }^{3,9-12}$ well-done studies have demonstrated continuing underutilization of VTE prophylaxis. ${ }^{3,4,9-12}$ The purpose of the current study was to assess patterns of practice for VTE prophylaxis to shed light on the appropriateness of care.

\section{METHODS}

\section{Setting and Design}

This cross-sectional study involved patients discharged from general internal medicine units at the University of Alberta Hospital in Edmonton, Alberta, from January 1 to September 30, 2015. This time frame was chosen to minimize the impact of new AHS VTE prophylaxis practice guidelines, released in late September and early October 2015, and associated educational sessions.

Eligible patients were those deemed to be at moderate to very high risk of VTE (Figure 1). Patients were excluded if they were less than 17 years old, had been admitted under services other than general internal medicine (such as surgery or intensive care), had a length of stay less than $72 \mathrm{~h}$, were receiving therapeutic anticoagulation, or were awaiting long-term care or palliative placement (documented within the first $72 \mathrm{~h}$ of admission), or if weight and/or renal function had not been documented.

Patient charts were identified by the Data Integration, Management, and Reporting service, duplicates were removed, and a random-sequence generator was used to identify 150 charts per quarter that aligned with the timing of the local quarterly audit. The target was 150 charts per quarter to ensure a sufficient number of charts for screening to reach the desired sample size. A convenience sample of 200 to 300 charts was targeted. Ethics approval was obtained from the Health Research Ethics Board Health Panel (Pro 00060302).

\section{Outcome Measures}

The primary outcome measure was the proportion of patients at moderate to very high risk of VTE admitted to a general internal medicine unit who received appropriate VTE prophylaxis within $24 \mathrm{~h}$ after admission. Definitions of thrombotic risk, absolute and relative contraindications to pharmacologic VTE prophylaxis, and appropriate VTE prophylaxis were based on local policy and guideline documents (Figure 1). ${ }^{13-16}$ To meet the criteria for appropriate VTE prophylaxis, the right drug, dose, frequency, and duration had to be prescribed 
(Figure 1). Renal function not requiring dosage adjustment was defined as creatinine clearance greater than or equal to 30 $\mathrm{mL} / \mathrm{min}$, as calculated by the Cockcroft-Gault equation. Insufficient duration of therapy was defined as cessation of VTE prophylaxis within $72 \mathrm{~h}$ of initiation, unless there was documentation of patient mobility or major bleeding. For those with multiple VTE prophylaxis orders in the first $72 \mathrm{~h}$ after admission, only the first order was assessed for appropriateness. Mechanical VTE prophylaxis was deemed appropriate if absolute or relative contraindications to pharmacologic prophylaxis were present (Figure 1).

Secondarily, the proportion of patients receiving appropriate VTE prophylaxis in this study was compared with that of local provincial audits, using data from the same medicine units over the same time interval. In addition, the frequency of patients not receiving appropriate VTE prophylaxis and the basis for deeming prophylaxis to be inappropriate (e.g., incorrect drug, dose, frequency, or duration) were reported. The proportion of at-risk patients who experienced a thrombotic or major bleeding event, regardless of the appropriateness of VTE prophylaxis (i.e., with either appropriate or inappropriate VTE prophylaxis), was also reported. For the duration of the patient's hospital stay, thrombotic events were defined on the basis of per-chart documentation (encompassing deep vein thrombosis, pulmonary embolism, or thromboembolism to another site, which may have included myocardial infarction, stroke, or portal vein thrombosis), whereas major bleeding was defined as fatal bleeding, symptomatic bleeding in a critical area or organ, bleeding causing a decrease in hemoglobin greater than or equal to $20 \mathrm{~g} / \mathrm{L}$, and/or transfusion of 2 or more units of whole blood or red blood cells. ${ }^{17}$

\section{Data Collection and Analysis}

A single data abstractor (A.M.) assessed each chart for VTE risk, appropriateness of VTE prophylaxis, occurrence of thrombotic or major bleeding events, and reason for deeming VTE prophylaxis to be inappropriate (if applicable). Data were collected using a standardized data collection form within the institution's Research Electronic Data Capture (REDCap) database. AHS local audit data were obtained from Tableau Audit Reports. ${ }^{18}$ Study data were downloaded directly from REDCap into an Excel 2011 file (Microsoft Corporation, Redmond, Washington), which was used to generate descriptive statistics. SPSS Statistics, version 19 (IBM, Armonk, New York) was used to perform a $t$ test for equality of means, in the comparison of study data with audit results.

\section{RESULTS}

In total, charts for 376 patients were screened, with 225 deemed to be at moderate to very high risk of VTE (Figure 2). The median patient age was 68 years, mean length of stay was 6 days, and the majority had creatinine clearance of at least

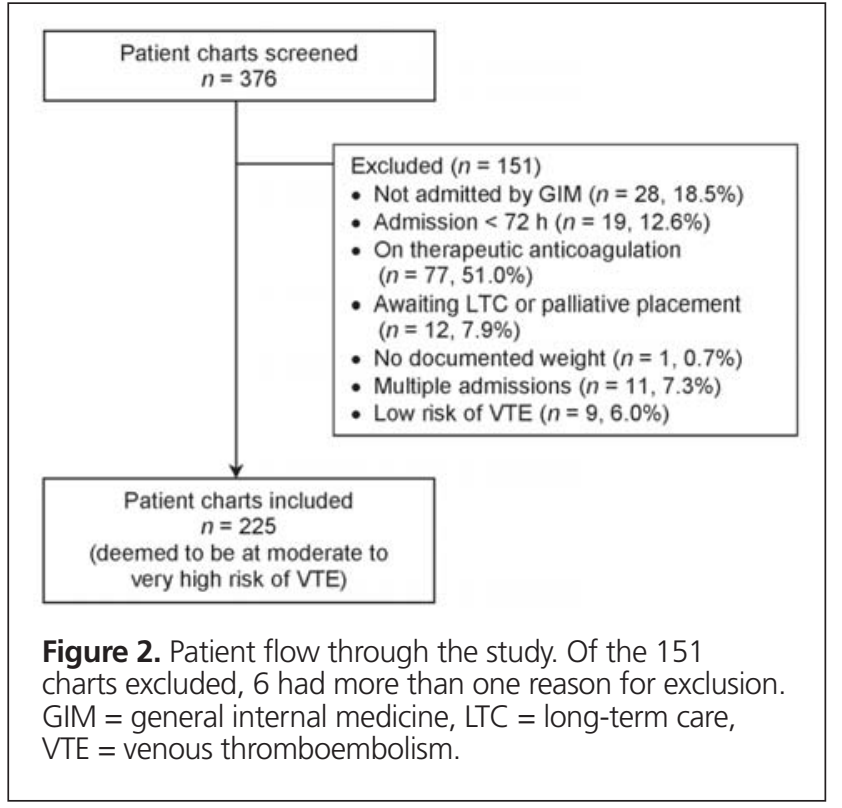

$30 \mathrm{~mL} / \mathrm{min}(195$ [86.7\%]) and body weight of 40-100 kg (209 [92.9\%]) (Table 1). In total, 179 (79.6\%) of these at-risk patients received appropriate VTE prophylaxis within $24 \mathrm{~h}$ after admission to a general internal medicine unit (Figure 3). The rate of appropriate VTE prophylaxis was lower in this study than in the local audits $(79.6 \%$ versus $97.6 \% ; t=-7.135 ; p=0.002)$.

Among the 46 patients with inappropriate VTE prophylaxis, $13(28.3 \%)$ were at moderate risk of VTE and 33 (71.7\%) were at high risk of VTE. The 2 most frequent reasons for deeming VTE prophylaxis to be inappropriate were not providing a mechanical method of VTE prophylaxis for patients with a bleeding contraindication (18 patients [39.1\%]) and wrong dose of pharmacologic prophylaxis (15 patients [32.6\%]) (Figure 3). All 13 patients with body weight above $100 \mathrm{~kg}$ received an incorrect dose, whereas 2 of the 3 patients weighing less than $40 \mathrm{~kg}$ received an incorrect dose.

In total, $2.7 \%(6 / 225)$ of the patients experienced a thrombotic event, irrespective of the appropriateness of VTE prophylaxis (Figure 3): 1.7\% (3/179) of those who received appropriate prophylaxis and $6.5 \%(3 / 46)$ of those who received inappropriate prophylaxis. Among the latter, VTE prophylaxis was deemed inappropriate because of insufficient duration of therapy (1 patient), a dose that was too high for a person with low body weight (1 patient), and a dose that was too low for a person with high body weight (1 patient).

In total, $7.6 \%(17 / 225)$ of these at-risk patients experienced a major bleeding event, irrespective of the appropriateness of VTE prophylaxis: $4.5 \%(8 / 179)$ of those who received appropriate prophylaxis and 19.6\% (9/46) of those who received inappropriate prophylaxis. Among the latter, VTE prophylaxis was considered inappropriate because mechanical prophylaxis alone was not provided for patients with bleeding contraindications 
This single copy is for your personal, non-commercial use only.

For permission to reprint multiple copies or to order presentation-ready copies for distribution, contact CJHP at cjhpedit@cshp.ca

Table 1. Baseline Characteristics

\begin{tabular}{|c|c|c|}
\hline Characteristic & \multicolumn{2}{|c|}{$\begin{array}{c}\text { No. (\%) of Patients* } \\
(n=225)\end{array}$} \\
\hline Age (years) (median and range) & 68 & $(18-98)$ \\
\hline Sex, male & 106 & $(47.1)$ \\
\hline Length of stay (days) (median and range) & 6 & $(3-156)$ \\
\hline Weight (kg) (mean \pm SD) & \multicolumn{2}{|c|}{$73.9 \pm 21.2$} \\
\hline$<40$ & 3 & $(1.3)$ \\
\hline $40-100$ & 209 & $(92.9)$ \\
\hline$>100$ & 13 & $(5.8)$ \\
\hline$\overline{\mathrm{CrCl}(\mathrm{mL} / \mathrm{min}) \dagger}$ & \multicolumn{2}{|c|}{$74.9 \pm 49.7$} \\
\hline $\mathrm{CrCl}<30 \mathrm{~mL} / \mathrm{min}$ & 30 & $(13.3)$ \\
\hline \multicolumn{3}{|l|}{ Risk stratification } \\
\hline Moderate & 68 & $(30.2)$ \\
\hline High & 153 & $(68.0)$ \\
\hline Very high & 4 & $(1.8)$ \\
\hline Contraindications to VTE prophylaxisł & 24 & $(10.7)$ \\
\hline HIT diagnosed during admission & 1 & $(4.2)$ \\
\hline Severe thrombocytopenia & 3 & $(12.5)$ \\
\hline Within $24 \mathrm{~h}$ of spinal puncture or epidural & 1 & $(4.2)$ \\
\hline Active bleeding & 15 & $(62.5)$ \\
\hline Gastrointestinal bleeding§ & 8 & $(53.3)$ \\
\hline Major epistaxis & 1 & $(6.7)$ \\
\hline Intracranial hemorrhage & 4 & $(26.7)$ \\
\hline Significant postoperative bleeding & 1 & $(6.7)$ \\
\hline Other & 1 & $(6.7)$ \\
\hline Severe coagulopathy & 5 & $(20.8)$ \\
\hline
\end{tabular}

$\mathrm{CrCl}=$ creatinine clearance, $\mathrm{HIT}=$ heparin-induced

thrombocytopenia, SD = standard deviation,

VTE $=$ venous thromboembolism

*Except where indicated otherwise.

+Cockcroft-Gault equation.

$\neq$ Within this section, percentages for subentries are based on denominators of 24 (for main contraindications) and 15 (for types of active bleeding).

$\S$ One patient had both active gastrointestinal bleeding and international normalized ratio $>2.0$

(5 patients), delayed start of VTE prophylaxis ( $>24 \mathrm{~h}$ after admission; 1 patient), a combination of no provision of mechanical prophylaxis in patients with bleeding complications and delayed start (2 patients), and order for pharmacologic prophylaxis during active bleeding, without administration (1 patient).

\section{DISCUSSION}

This cross-sectional study showed that $79.6 \%$ of patients with moderate to very high risk of VTE received appropriate prophylaxis within $24 \mathrm{~h}$ after admission to general internal medicine units, a rate significantly lower than that reported by the local provincial audit (97.6\%). Given that AHS has set an institutional accreditation target of $85 \%$, these results suggest that general internal medicine units were performing below accreditation standards. However, this difference may be attributed to several factors. First, this study had a larger sample size than the provincial audits, which allowed a more accurate reflection of current prescribing practice. The University of
Alberta had audits performed and reported every 3 months, in which 2 auditors randomly audited a minimum of 20 charts (total) from various units for appropriateness of VTE prophylaxis, using criteria set forth by AHS clinical policy and patient care orders for VTE prophylaxis in adults. Second, the criteria for appropriateness of VTE prophylaxis set forth by policy and guidance documents for the local audits were more liberal than the study definitions. For example, graduated compression stockings were considered appropriate according to the provincial audit criteria but were not considered appropriate in the current study. Furthermore, as per the study protocol, if a patient had multiple VTE prophylaxis orders during the first $72 \mathrm{~h}$ after admission, only the first order was assessed for appropriateness of VTE prophylaxis, according to creatinine clearance and body weight. In contrast, the provincial audits assess appropriateness of VTE prophylaxis at any time during a patient's stay, and the audit is not limited to the first order. Hence, orders that have been changed to improve the appropriateness of dosing may be included in the provincial audit, even if the original order was inappropriate. Methodological differences between the current study and the local audits contributed to the discrepancy in rates of appropriate VTE prophylaxis, highlighting variability in assessing the appropriateness of VTE prophylaxis across the province.

Of the $20.4 \%$ of at-risk patients who received inappropriate VTE prophylaxis, the most frequently reported reason was not providing mechanical methods for VTE prophylaxis for patients with a bleeding contraindication (39.1\%). Although mechanical VTE prophylaxis was warranted in several cases, sequential compression devices were available in only 1 of 3 general internal medicine units. In addition, use of these devices requires increased nursing support and ultimately may be poorly tolerated because of patient discomfort, which may in turn result in decreased adherence. For one-third of the patients with inappropriate prophylaxis, the dose was incorrect: either too low for a person with high body weight $(28.3 \%)$ or too high for a person with low body weight (4.3\%). All of the patients who weighed more than $100 \mathrm{~kg}$, and 2 of the 3 patients who weighed less than $40 \mathrm{~kg} \mathrm{had}$ incorrect doses of VTE prophylaxis. A provincial preprinted care order for VTE prophylaxis providing dosing guidance was available to all AHS institutions, but all of the general internal medicine units at the University of Alberta Hospital were using preprinted admission care orders that lacked guidance about dose adjustment for those at the extremes of weight and those with renal dysfunction. This finding emphasizes the lack of clarity and understanding in relation to VTE prophylaxis at the extremes of weight and indicates the importance of intervention by clinical pharmacists.

The discrepancy between these findings and local audit results, as well as the identified areas of inappropriate use, offers insight into barriers that must be overcome to optimize VTE prophylaxis. A lack of awareness of the clinical importance of VTE prophylaxis, a belief that the risks of bleeding with VTE 
This single copy is for your personal, non-commercial use only.

For permission to reprint multiple copies or to order presentation-ready copies for distribution, contact CJHP at cjhpedit@cshp.ca

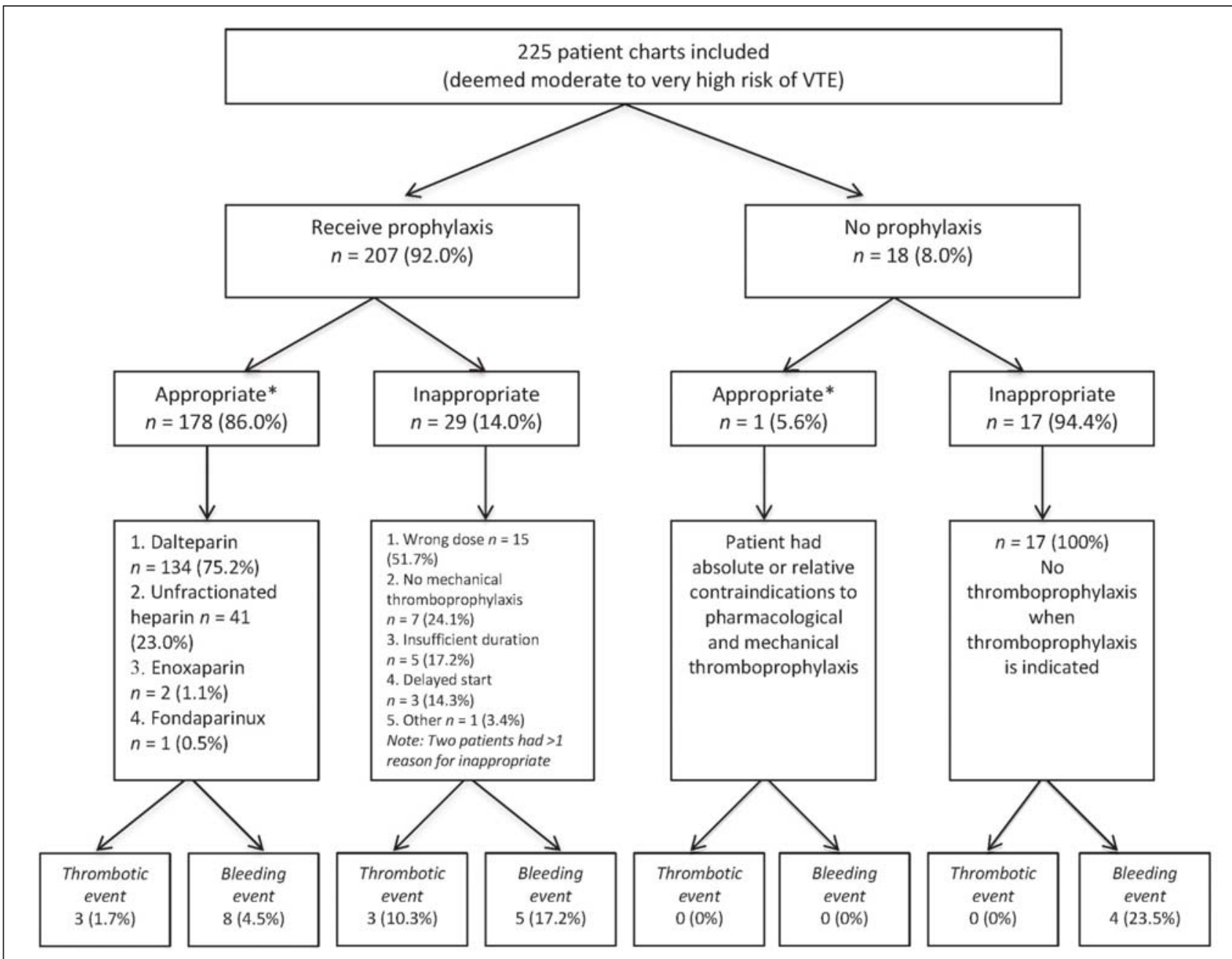

Figure 3. Use of venous thromboembolism prophylaxis. *Overall rate of appropriate prophylaxis was 79.6\% (179/225).

prophylaxis are too high, a perceived lack of clarity within the existing guidelines, and disagreements about interpretation of existing recommendations all contribute to improper use of VTE prophylaxis. ${ }^{4,12,17}$ Several initiatives could be undertaken to overcome existing barriers and to improve consistent provision of appropriate VTE prophylaxis. Educational sessions, preprinted order sets detailing VTE prophylaxis in relation to various patient criteria (e.g., renal dysfunction, extremes of weight), and computer reminders may all have a role in increasing recognition of the importance of VTE prophylaxis. ${ }^{19}$ Communication of audit results through an audit and feedback process within a multidisciplinary health care team could increase clinician awareness and address potential misconceptions about VTE prophylaxis. The findings of this study indicate opportunities to improve VTE prophylaxis by specifically targeting the use of mechanical VTE prophylaxis and by improving pharmacologic dosing at the extremes of weight and in patients with decreased renal function. Other regions have found that although rates of appropriate prophylaxis increased with use of a VTE-specific preprinted order set facilitating appropriate dosing and risk assessment, uptake of the form declined over time. ${ }^{19}$ However, the practice of embedding VTE orders in a preprinted form may create an educational and treatment tool. A multidisciplinary and multifaceted approach targeting various health care professionals would be beneficial in overcoming several barriers. In particular, engaging pharmacists to ensure appropriate drug dosing for unique populations would target one of the areas with the highest rates of inappropriate VTE prophylaxis.

This study had some limitations. First, as a retrospective analysis, all end points were subject to documentation provided in the chart. As such, it was not possible to follow patients after discharge, and we acknowledge that thromboembolic events may have occurred soon after the patients went home. Second, these data may not reflect current prescribing practices, because educational initiatives, including educational sessions and updated standards, were implemented at the study institution in late 
This single copy is for your personal, non-commercial use only.

For permission to reprint multiple copies or to order presentation-ready copies for distribution, contact CJHP at cjhpedit@cshp.ca

September and early October 2015. Third, the study method required assessment of the order for VTE prophylaxis within the first $24 \mathrm{~h}$ of admission to a general internal medicine unit and included only patients with length of stay longer than $72 \mathrm{~h}$. The order written within $24 \mathrm{~h}$ of admission was selected because the objective was to determine how VTE prophylaxis was prescribed, not how it may eventually be modified or altered by any member of the health care team. The target population was patients with length of stay longer than $72 \mathrm{~h}$ to ensure a sufficient time in hospital to appropriately assess the duration of VTE prophylaxis. Both of these factors may have led to a lower rate of appropriate use of VTE prophylaxis relative to audit data.

\section{CONCLUSION}

The results of this study provide insight into current prescribing patterns for VTE prophylaxis within the general internal medicine units of the study institution. Although these results reflect lower-than-desired rates of VTE prophylaxis, variation in definitions and data collection may have contributed to the discrepancy. Measures to improve rates of VTE prophylaxis may include systematic updates to the preprinted care orders used at the time of admission to general internal medicine units to include dosing guidance related to extremes of weight and presence of renal dysfunction. In addition, engagement of the health care team may contribute to closing the gap between evidence-based guidelines and prescribing practice.

\section{References}

1. Næess IA, Christiansen SC, Romundstad P, Cannegieter SC, Rosendaal FR, Hammerstrøm J. Incidence and mortality of venous thrombosis: a population-based study. J Thromb Haemost. 2007;5(4):692-9.

2. Cohen AT, Tapson VF, Bergmann JF, Goldhaber SZ, Kakkar AK, Deslandes $\mathrm{B}$, et al. Venous thromboembolism risk and prophylaxis in the acute hospital care setting (ENDORSE study): a multinational cross-sectional study. Lancet. 2008;371(9610):387-94.

3. Kahn SR, Panju A, Geerts W, Pineo GF, Desjardins L, Turpie AG, et al. Multicenter evaluation of the use of venous thromboembolism prophylaxis in acutely ill medical patients in Canada. Thromb Res. 2007;119(2):145-55.

4. Kahn SR, Lim W, Dunn AS, Cushman M, Dentali F, Akl EA, et al. Prevention of VTE in nonsurgical patients: antithrombotic therapy and prevention of thrombosis, 9th ed: American College of Chest Physicians evidence-based clinical practice guidelines. Chest. 2012;141(2 Suppl):e195S-226S.

5. Kahn SR, Morrison DR, Cohen JM, Emed J, Tagalakis V, Roussin A, et al. Interventions for implementation of thromboprophylaxis in hospitalized medical and surgical patients at risk for venous thromboembolism. Cochrane Database Syst Rev. 2013;(7):CD008201.

6. Kleinbart J, Williams MV, Rask K. Chapter 31: Prevention of venous thromboembolism. In: Making health care safer: a critical analysis of patient safety practices. Evidence reportttechnology assessment no. 43. AHRQ Publication No. 01-E058. Rockville (MD): Agency for Healthcare and Quality; 2001 [cited 2017 May 22]. Available from: https://archive.ahrq.gov/clinic/ ptsafety/chap31a.htm

7. Required organizational practices handbook 2015. Ottawa (ON): Accreditation Canada; 2015.

8. National VTE audit day: results and feedback. Edmonton (AB): Canadian Patient Safety Institute; 2014 [cited 2016 May 21]. Available from: www. patientsafetyinstitute.ca/en/toolsResources/Presentations/2014Webinars/Pages/ National-VTE-Audit-Day-Results-and-Feedback.aspx

9. Lamy A, Wang X, Kent R, Smith K, Gafni A. Economic evaluation of the MEDENOX trial: a Canadian perspective. Can RespirJ. 2002;9(3):169-77.
10. Samama MM, Cohen AT, Darmon JY, Desjardins L, Eldor A, Janbon C, et al.; Prophylaxis in Medical Patients with Enoxaparin Study Group. A comparison of enoxaparin with placebo for the prevention of venous thromboembolism in acutely ill medical patients. $N$ Engl J Med. 1999; 341(11):793-800.

11. Leizorovicz A, Cohen AT, Turpie AG, Olsson CG, Vaitkus PT, Goldhaber SZ; PREVENT Medical Thromboprophylaxis Study Group. Randomized, placebo-controlled trial of dalteparin for the prevention of venous thromboembolism in acutely ill medical patients. Circulation. 2004;110(7):874-9.

12. de Lissovoy G, Subedi P. Economic evaluation of enoxaparin as prophylaxis against venous thromboembolism in seriously ill medical patients: a US perspective. Am J Manag Care. 2002;8(12):1082-8.

13. Venous thromboembolism prophylaxis [practice support document guideline]. Document PS-09-01. Edmonton (AB): Alberta Health Services; 2012 [cited 2015 Jul 22]. Available from: https://extranet.ahsnet.ca/teams/ policydocuments/1/clp-venous-thromboembolism-prophylaxis-ps-09-01guideline.pdf

14. VTE prophylaxis adult patient care orders. Edmonton (AB): Alberta Health Services; 2015 [cited 2015 Jul 22]. Available from: https://myahs.ca/insite/ assets/acrd/tms-acrd-data-group-orderset-doublesided-sample.pdf. Login required to access content.

15. Venous thromboembolism prevention (VTE): getting started kit components. Edmonton (AB): Canadian Patient Safety Institute; 2012 May [updated 2017 Jan; cited 2015 Jul 27]. Available from: www.patientsafetyinstitute.ca/ en/toolsResources/VTE-Getting-Started-Components/Pages/default.aspx

16. AHS VTE prophylaxis VTE audit legend. Edmonton (AB): Alberta Health Services, VTE Prophylaxis Accreditation ROP Working Group; 2014 [cited 2015 Sep 3]. Available from: https://myahs.ca/insite/Accreditation/tmsacrd-cpsi-audit-legend.pdf. Login required to access content.

17. Schulman S, Kearon C. Definition of major bleeding in clinical investigations of antihemostatic medicinal products in non-surgical patients. J Thromb Haemost. 2005;3(4):692-4.

18. VTE prophylaxis audit reports. In: Tableau audit reports. Edmonton (AB): Alberta Health Services, Clinical Quality Metrics-Analysis; 2015 [cited 2015 Sep 3]. Accessed via institutional intranet.

19. Semchuk W, Kolodziejak L, Bubbar C; International Society on Thrombosis and Haemostasis Scientific and Standardization Committee, Subcommittee on Control of Anticoagulation. Poulin S. Working toward a system-wide venous thromboembolism prophylaxis strategy: experience from a multisite health region. Hosp Pharm. 2011;46(8):574-9.

Allison Mejilla, BScPharm, ACPR, is with Pharmacy Services, University of Alberta Hospital, Alberta Health Services, Edmonton, Alberta.

Micheal Guirguis, BScPharm, PhD, is with Pharmacy Services, University of Alberta Hospital, Alberta Health Services, Edmonton, Alberta.

Sheri Koshman, BScPharm, PharmD, is with the Faculty of Medicine and Dentistry, University of Alberta, Edmonton, Alberta.

Tammy J Bungard, BSP, PharmD, is with the Faculty of Medicine and Dentistry, University of Alberta, Edmonton, Alberta.

Competing interests: For work unrelated to this article, Tammy Bungard has received speakers' honoraria from Bristol Myers Squibb and Bayer and unrestricted grants from Bristol Myers Squibb-Pfizer and Bayer. No other competing interests were declared.

\section{Address correspondence to:}

Dr Tammy J Bungard

EPICORE Centre

362 Heritage Medical Research Centre

University of Alberta

Edmonton $A B$ T6G 252

e-mail: tammy.bungard@ualberta.ca

Funding: None received.

Acknowledgements: The authors gratefully acknowledge Rita Pon and Keith King (Alberta Health Services) for providing insight on the study protocol. 